\title{
Transcriptomics-based screen for genes induced by flagellin and repressed by pathogen effectors identifies a cell wall-associated kinase involved in plant immunity
}

\author{
Hernan G Rosli ${ }^{1,2}$, Yi Zheng ${ }^{1}$, Marina A Pombo ${ }^{1}$, Silin Zhong ${ }^{1,3}$, Aureliano Bombarely ${ }^{1}$, Zhangjun Fei ${ }^{1}$, \\ Alan Collmer ${ }^{4,5}$ and Gregory B Martin ${ }^{1,4,5^{*}}$
}

\begin{abstract}
Background: Microbe-associated molecular patterns, such as those present in bacterial flagellin, are powerful inducers of the innate immune response in plants. Successful pathogens deliver virulence proteins, termed effectors, into the plant cell where they can interfere with the immune response and promote disease. Engineering the plant immune system to enhance disease resistance requires a thorough understanding of its components.

Results: We describe a high-throughput screen, using RNA sequencing and virus-induced gene silencing, to identify tomato genes whose expression is enhanced by the flagellin microbe-associated molecular pattern flgll-28, but reduced by activities of the Pseudomonas syringae pv. tomato (Pst) type III effectors AvrPto and AvrPtoB. Gene ontology terms for this category of Flagellin-induced repressed by effectors (FIRE) genes showed enrichment for genes encoding certain subfamilies of protein kinases and transcription factors. At least 25 of the FIRE genes have been implicated previously in plant immunity. Of the 92 protein kinase-encoding FIRE genes, 33 were subjected to virus-induced gene silencing and their involvement in pattern-triggered immunity was tested with a leaf-based assay. Silencing of one FIRE gene, which encodes the cell wall-associated kinase SIWAK1, compromised the plant immune response resulting in increased growth of Pst and enhanced disease symptoms.

Conclusions: Our transcriptomic approach identifies FIRE genes that represent a pathogen-defined core set of immune-related genes. The analysis of this set of candidate genes led to the discovery of a cell wall-associated kinase that participates in plant defense. The FIRE genes will be useful for further elucidation of the plant immune system.
\end{abstract}

\section{Background}

The plant immune system involves two related inducible responses. The first response is activated by the detection of microbe-associated molecular patterns (MAMPs) by the extracellular domains of pattern recognition receptors (PRRs) [1]. A small number of PRRs have been identified in plants that recognize MAMPs derived from flagellin, elongation factor $\mathrm{Tu}$, an ethylene-inducing xylanase, and certain non-proteinaceous MAMPs [2].

\footnotetext{
* Correspondence: gbm7@cornell.edu

'Boyce Thompson Institute for Plant Research, Ithaca, NY 14853, USA ${ }^{4}$ Department of Plant Pathology and Plant-Microbe Biology, Cornell University, Ithaca, NY 14853, USA

Full list of author information is available at the end of the article
}

Additionally, damage-associated molecular patterns (DAMPs), which typically appear in the apoplast as a consequence of pathogen attack, function as host-derived elicitors [3]. The activation of pattern-triggered immunity (PTI) by MAMPs and DAMPs leads to changes in the intracellular calcium concentration, production of reactive oxygen species, activation of mitogen-activated protein kinase (MAPK) cascades and transcriptional reprogramming [4]. These events lead, in a largely unknown manner, to inhibition of pathogen growth and suppression of disease. Successful pathogens deliver virulence proteins (effectors) into the plant cell and a majority of these proteins appear to function by interfering with host immunity-associated events triggered by MAMP recognition [5]. A second plant 
defense response, effector-triggered immunity (ETI), can be activated in cases where a specific pathogen effector or its activity is recognized by a host nucleotide-binding leucinerich repeat-containing (NB-LRR) resistance protein [1].

The interaction of tomato with Pseudomonas syringae pv. tomato (Pst) is a powerful model system for understanding the molecular basis of bacterial pathogenesis and plant immunity [6]. Pst enters the apoplastic space of tomato leaves through stomata or wound sites. The plant responds to Pst even at the stomatal entry stage, although the bacterium can overcome this response with the aid of the phytotoxin coronatine [7]. Pst present in the apoplast is detected by PRR-mediated recognition of various MAMPs thereby activating PTI. The best characterized of these MAMPs is a 22-amino acid region of flagellin (flg22), which is recognized by FLS2, a PRR with extracellular leucine-rich repeats (LRRs) and an intracellular protein kinase domain [8]. The mechanism by which FLS2 activates intracellular events involves another LRR receptor-like kinase, BAK1, as well as cytoplasmic protein kinases of the PBS1-like family [9-11]. Recently, another MAMP derived from flagellin, flgII-28, has been identified [12]. The PRR that detects flgII-28 is unknown, but it appears to play an important role in activating PTI in solanaceous species [13].

Two Pst effector proteins, AvrPto and AvrPtoB, have been studied extensively and found to play multiple important roles during the tomato-Pst interaction [14]. These roles are partially redundant and deletion of both effector genes is required before a marked decrease in virulence is observed. Some of this redundancy is attributable to the fact that each effector binds and interferes with protein kinase domains of the FLS2-BAK1 complex, thereby disrupting the host response to flg22 [14]. However, each effector targets additional host proteins using independent domains found in each effector $[15,16]$. In a well-studied example of ETI, the host protein kinases Fen and Pto appear to act as decoys of the real kinase virulence targets. Interaction of AvrPto and AvrPtoB with these decoys triggers a host immune response mediated through the NB-LRR protein Prf [17].

Host responses associated with PTI and ETI are complex and have been studied by both reductionist approaches focused on individual components and mechanisms as well as by large-scale systems biology approaches looking at the totality of metabolomic, proteomic and transcriptomic changes. Previous transcriptomic studies in Arabidopsis thaliana, tomato and other species have relied primarily on microarrays and cDNA-amplified fragment length polymorphism (AFLP) methods, which, though limited in their dynamic range and, in some cases, in their genome coverage, have yielded important insights into PTI, ETI and the role of pathogen effectors in suppressing the former responses [18-25]. However, the emergence of RNA sequencing (RNA-seq) and associated statistical analyses as well as the availability of improved gene annotation now allows for the development of a much more comprehensive view of subtle gene expression changes, and how pathogen effectors impact these changes as part of their immunity-suppressive activities. Here we have taken advantage of the recently completed tomato genome sequence [26], the comprehensive nature of RNA-seq analysis, virus-induced gene silencing (VIGS) and the well-characterized tomato-Pst system to develop a genome-wide screen for genes whose expression is specifically altered in response to both MAMP detection and subsequent activities of pathogen effectors.

\section{Results}

Development of an RNA sequencing approach to examine the plant response to MAMPs present in various bacterial pathogens and non-pathogens

To characterize the PTI response of tomato and the effect of the delivery of a subset of effectors, we performed an RNA-seq analysis of tomato Rio Grande prf3 leaves challenged with either the flgII-28 peptide or the bacterial strains described in Table 1 . We focused on flgII-28 because it has recently emerged as a second MAMP derived from flagellin, in addition to flg22, which is perceived specifically by solanaceous species $[12,13]$. In this case we chose $1 \mu \mathrm{M}$ concentration, which is the same as the lowest amount used for flg22 treatments in previous microarray studies of Arabidopsis [19,23]. Using Pseudomonas fluorescens, Pseudomonas putida and flgII28 we investigated PTI-associated transcriptional changes, while Agrobacterium tumefaciens and Pseudomonas syringae pv. tomato (Pst) strain DC3000 $\Delta h r c Q-U \Delta f l i C$ were chosen to examine the effects due to MAMPs other than flagellin. The comparison between the response to DC3000 and the mutant DC3000 2 avrPto $\triangle a v r P t o B$ was designed to uncover the effect of two 'early-acting' type III effectors [27]. We chose a sampling time $(6 \mathrm{~h})$ and a bacterial titer $\left(5 \times 10^{6} \mathrm{cfu} / \mathrm{mL}\right)$ to capture early PTI-associated transcriptional changes and also the effects of early-acting effectors on these changes. For both the non-pathogenic Pseudomonas species and A. tumefaciens we used the same time but a higher titer $\left(10^{8} \mathrm{cfu} / \mathrm{mL}\right)$ to maximize the plant response.

The RNA-seq analysis over all treatments revealed reads per kilobase of exon model per million mapped reads (RPKM) ranging from 0 to approximately 39,000 for the 34,727 genes predicted in tomato [26]. We focused on genes with $\geq 3$ RPKM in at least one treatment based on analysis of the RPKM of genes known to play a role in immunity (Additional file 1: Figure S1). We refer to this group of 17,597 genes as the expressed genes. All of our RNA-seq data are available from the Tomato 
Table 1 Details of the treatments used for RNA sequencing analysis of the tomato immune response

\begin{tabular}{|c|c|c|}
\hline Treatment & Concentration & Comment \\
\hline flgll-28 & $1 \mu \mathrm{M}$ & 28-amino acid peptide from Pseudomonas syringae pv. tomato T1 \\
\hline Pseudomonas syringae pv. tomato (Pst) DC3000 & $5 \times 10^{6} \mathrm{cfu} / \mathrm{mL}$ & Wild-type Pst strain \\
\hline 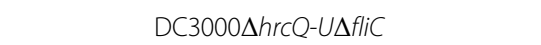 & $5 \times 10^{6} \mathrm{cfu} / \mathrm{mL}$ & DC3000 mutant, lacking a functional T3SS and flagellin \\
\hline DC3000 $\Delta$ avrPto $\Delta$ avrPto B & $5 \times 10^{6} \mathrm{cfu} / \mathrm{mL}$ & DC3000 mutant, with a functional T3SS, but lacking avrPto and avrPto $B$ \\
\hline Pseudomonas fluorescens 55 & $10^{8} \mathrm{cfu} / \mathrm{mL}$ & Soil bacterium \\
\hline Pseudomonas putida KT2240 & $10^{8} \mathrm{cfu} / \mathrm{mL}$ & Soil bacterium \\
\hline Agrobacterium tumefaciens GV2260 & $10^{8} \mathrm{cfu} / \mathrm{mL}$ & Disarmed plant pathogen \\
\hline $\mathrm{MgCl}_{2}$ & $10 \mathrm{mM}$ & Mock treatment \\
\hline- & - & Untreated plants \\
\hline
\end{tabular}

T3SS: type III secretion system; cfu: colony-forming units.

Functional Genomics Database [28] under accession no. D007.

Flagellin-derived peptides are the major MAMPs causing immunity-associated transcriptional changes in tomato A first analysis of the genes whose transcript abundance was affected by the treatments (Figure 1) revealed two main groups based on the overall change compared to the mock treatment ( $\geq 2$ fold and $P<0.05$ ). One group had a small number of genes $(<250 ; A$. tumefaciens, DC3000 $4 h r c Q-U \Delta f l i C)$ while the other had a much larger number ( $>900$; all the remaining treatments). These two extreme responses were associated with the presence or absence of a 'perceivable' flagellin (FliC protein) in the treatment. FliC in A. tumefaciens is divergent from other flagellin proteins perceived by plants, with a non-active flg22 region and probably a non-perceivable flgII-28 region due to a lack of conserved amino acids in this region (Additional file 2: Figure S2). The DC3000 $4 r c Q-U \Delta f l i C$ mutant lacks flagellin but, as with $A$. tumefaciens, would still have other MAMPs. However, our results indicate that in tomato other MAMPs play a minor role in gene expression changes observed at $6 \mathrm{~h}$. A common feature in the second group of treatments is the presence of flagellin or a portion thereof (flgII-28). In general, for these treatments more genes are induced than suppressed, and this trend was also observed when protein kinase and transcription factor (TF) genes were analyzed separately (Figure 1). Even though the titers used for P. fluorescens and $P$. putida were the same, the number of genes affected

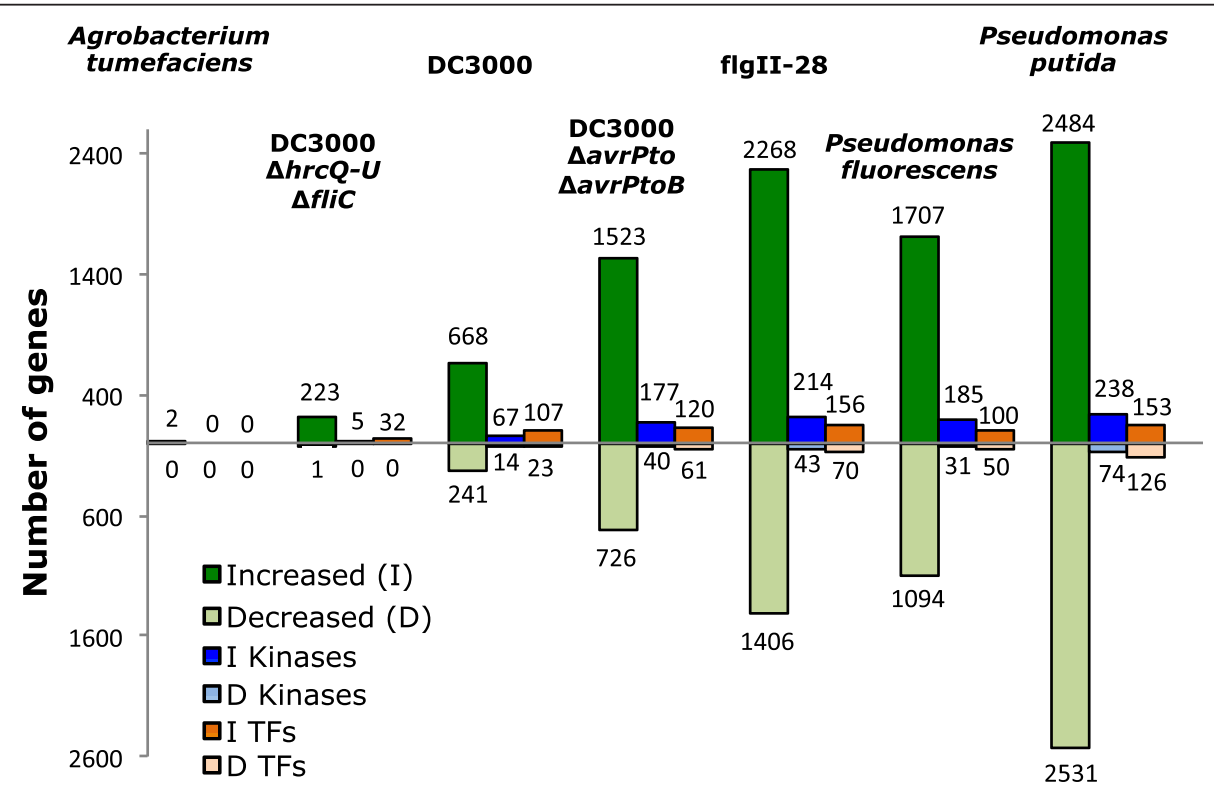

Figure 1 Flagellin contains the major MAMPs impacting transcriptional reprogramming following Pseudomonas syringae infiltration into tomato leaves. Shown is the total number of genes, protein kinases (kinases) and transcription factors (TFs) with increased (I) or decreased (D) transcript abundance compared to the mock, $6 \mathrm{~h}$ after treatment. A $\geq 2$-fold difference and $P<0.05$ were used as cut-offs. The number of genes in each category is also shown. See Table 1 for details of the treatments. 
by $P$. putida was higher, suggesting a more robust PTI response similar to that observed previously in Nicotiana benthamiana [29]. There are 1,148 protein kinase genes predicted in tomato (3.3\% of the 34,727 gene models [30]). In our treatments, protein kinase genes represented between $7 \%$ and $11 \%$ of the induced genes, indicating an enrichment similar to that observed in Arabidopsis upon flg22 treatment [19].

We found there was high degree of overlap in the genes whose expression changed in response to the flgII-28 peptide and different bacterial strains with perceivable flagellin: DC3000 $\Delta$ avrPto $\Delta a v r P t o B$ (90\% overlap), P. fluorescens (86\%) and P. putida (74\%) (Figure 2, see Additional file 3: Figure S3 for overlap of suppressed genes). This observation, and the fact that we found very little transcriptional reprogramming due to DC3000 $\Delta h r c Q-U \Delta f l i C$ infiltration indicates that flagellin-derived MAMPs (flg22 and flgII-28) have the greatest impact on tomato gene expression changes at the $6 \mathrm{~h}$ time point.

\section{The activities of AvrPto and AvrPtoB counteract a} subset of the transcriptional changes that occur upon flagellin perception

We next performed a clustering analysis of both treatments and genes. For this purpose we focused on the 4,150 genes that had $\geq 3$-fold difference between the maximum and the minimum RPKM observed for any two treatments. The genes grouped into two large clusters (Figure 3) each with a similar number of genes, with cluster A encompassing genes having decreased transcript abundance for flagellin-associated treatments and cluster B having genes with the opposite response. Cluster A is enriched in gene ontology (GO) terms such as photosynthesis, chloroplast and chlorophyll binding (Figure 3, see Additional file 4: Table S1 for a complete list of enriched terms). In contrast, cluster B is enriched in terms associated with defense response, plasma membrane and transmembrane receptor protein kinase activity.

The treatments also grouped into two distinct clusters (Figure 3). One cluster included treatments associated with flagellin perception (flgII-28, DC3000 $\Delta a v r P t o \Delta a v r P t o B$, P. fluorescens and P. putida) and the other consisted of 'flagellin-independent' treatments (mock, A. tumefaciens and DC3000 $\Delta h r c Q-U \Delta f l i C$ ). Interestingly, DC3000, which expresses a perceivable flagellin, clustered with this second group. This observation is consistent with the known role of AvrPto and AvrPtoB in interfering with FLS2 and BAK1, components of flagellin perception [14], and raised the possibility that the suppressed genes play particularly important roles in the plant defense response.

The subset of genes induced by flgll-28 but suppressed by AvrPto/AvrPtoB is enriched in gene ontology terms associated with the cell periphery, biotic interactions and signal transduction

We focused on the set of genes whose expression is increased by flgII-28 and is higher in DC3000_avrPto$\triangle a v r P t o B$ compared to DC3000 treatment. These are genes for which AvrPto and AvrPtoB activity appears to counteract the transcriptional increase due to flagellin perception. We refer to these as FIRE genes (for flagellininduced, repressed by effectors). From 2,268 genes that are increased by flgII-28 treatment (Figure 1), 622 are FIRE genes ( $\geq 2$ fold and $P<0.05$; see Additional file 5: Table S2).
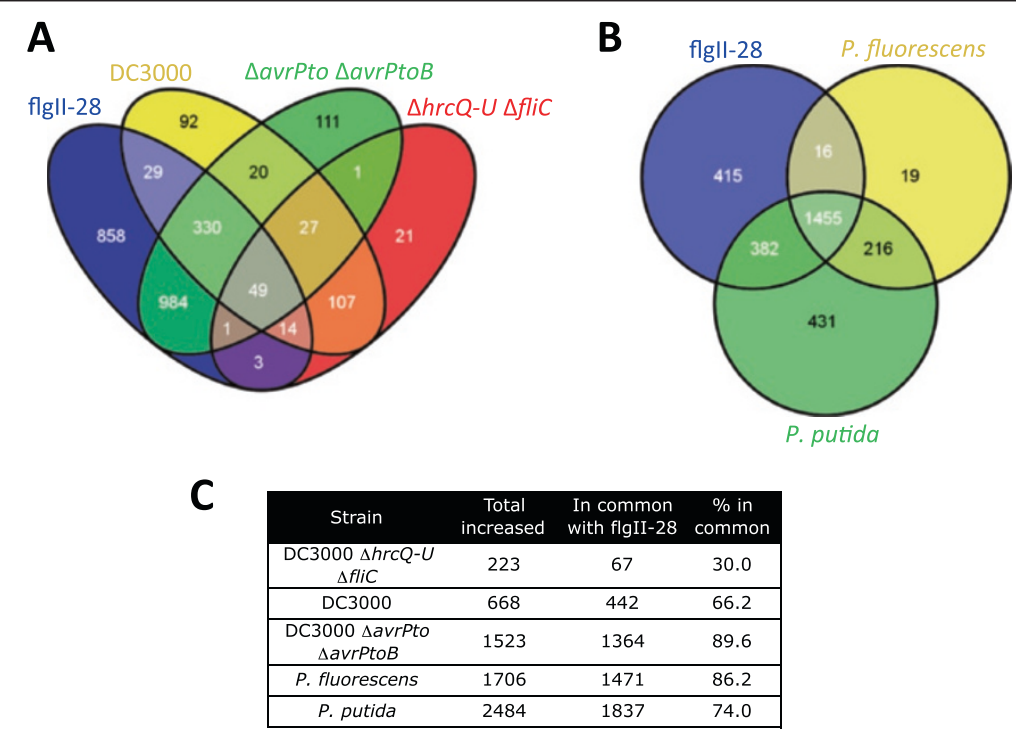

Figure 2 Overlap between genes induced by bacterial strains and flgll-28 treatment. (A) Overlap between Pseudomonas syringae pv. tomato strains and flgll-28; (B) Overlap between soil Pseudomonas and flgll-28. (C) Degree of overlap shown as percentage of genes. 


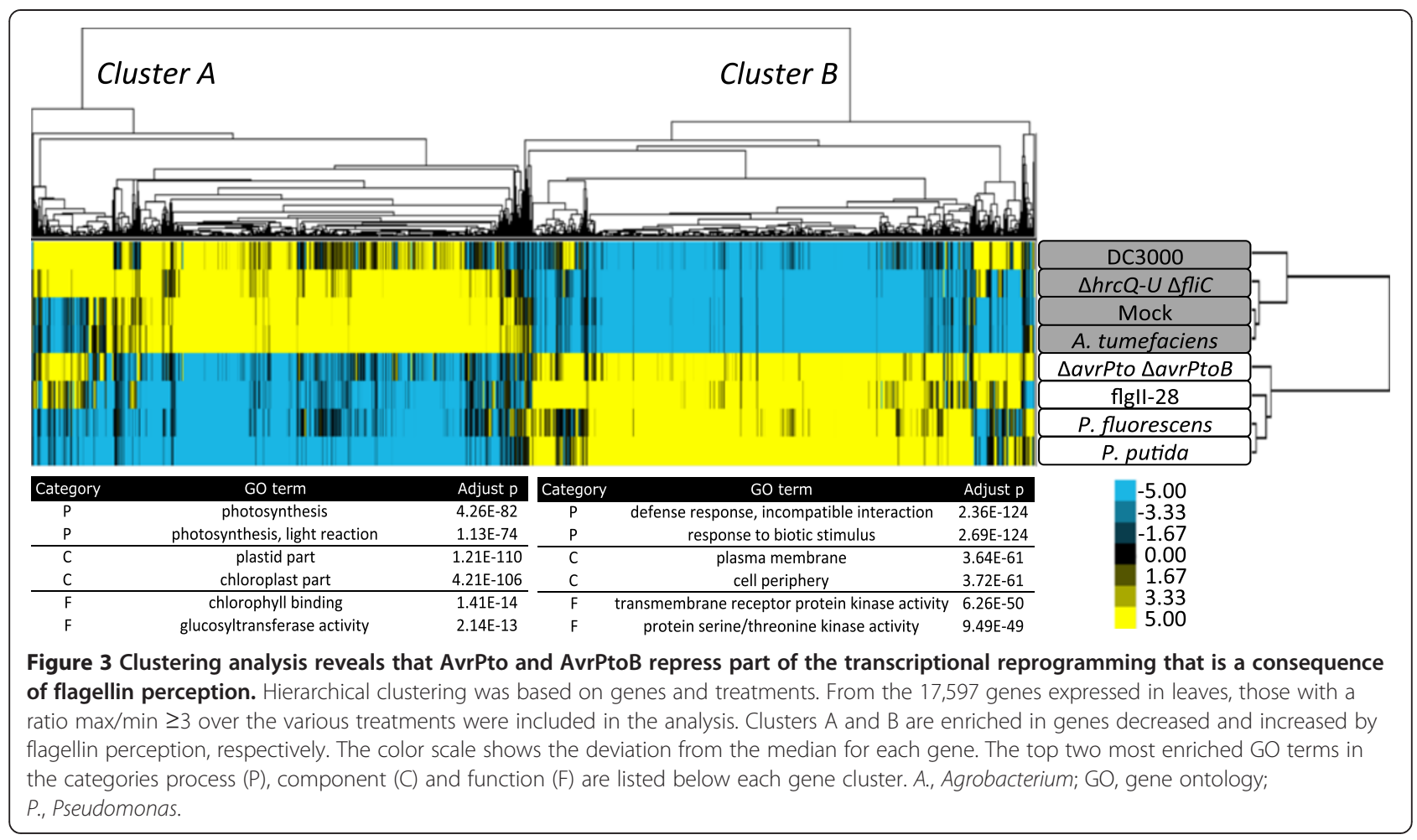

A GO term analysis of these 622 FIRE genes using the tomato genome as a reference would not be informative, since they derive from a list of genes induced by flgII- 28 and are therefore already enriched in immunity-related terms as described for cluster B (Figure 3). For this reason we used the 2,268 genes induced by flgII-28 as the reference. With this approach we found that the FIRE genes are enriched, even within the flgII-28-induced gene subset, for immune-related terms and particularly for protein kinases and transmembrane receptors (Additional file 6: Table S3). A total of 92 protein kinase-encoding genes are among the FIRE genes including many that have a known role in the immune response: FLS2.2, Bti9, RIN4.1, RIN4.2, Pti4 and Lectin RLK VI.2 (Additional file 5: Table S2). Furthermore, if we had used a less stringent cut-off for defining the FIRE gene list $(\geq 1.5$ fold change and $P<0.05)$ we would have included eight additional immunity-related genes such as SOBIR1, SAG101 and TFT7 (See Additional file 5: Table S2 for a complete list of genes).

Given the known importance of protein kinases in the immune response, we investigated the families that were affected by our treatments (Figure 4). From the 67 protein kinase families present in tomato [30], 43 were affected by flgII-28 treatment. Some families contained only genes induced by flgII-28 (for example, ankyrin repeat kinases, CTR1/EDR1, MAP2K and MAP3K) and others contained only genes with decreased expression in response to flgII-28 (for example, LRRK IV and VII and RLCK VI). Over $40 \%$ of the kinase genes increased by flgII-28 $(92 / 214)$ were found to be FIRE genes.

\section{Silencing of a FIRE gene encoding a cell wall-associated} kinase (SIWAK1) compromises pattern-triggered immunity To investigate the possible contribution to immunity of FIRE genes encoding protein kinases, we selected 33 such genes, including at least one member of each kinase category, for analysis using virus-induced gene silencing (VIGS) in N. benthamiana (Additional file 5: Table S2). Silenced plants were subjected to a cell death suppression assay (CDSA) [29] to test the involvement of the candidate gene in PTI. Briefly this assay consists of an initial infiltration of P. fluorescens as an inducer of PTI, then $8 \mathrm{~h}$ later the infiltration of DC3000 (partially overlapping with the first infiltration) as a challenger of this induction. If silencing of a candidate gene results in a faster breakdown of $P$. fluorescens protection, this is an indication that the gene contributes to PTI. VIGS constructs containing a gene fragment from FLS2 or an Escherichia coli-derived DNA fragment ( $E C 1$, see Materials and methods) served as positive and negative controls, respectively. From among the 33 candidates, we found a cell wall-associated kinase (WAK) gene (SlWAK1, Solyc09g014720), whose silencing compromised PTI-associated cell death suppression (Figure 5A). SlWAK1-silenced plants were morphologically similar to FLS2 and EC1 silencing controls (Additional file 7: Figure S4). 


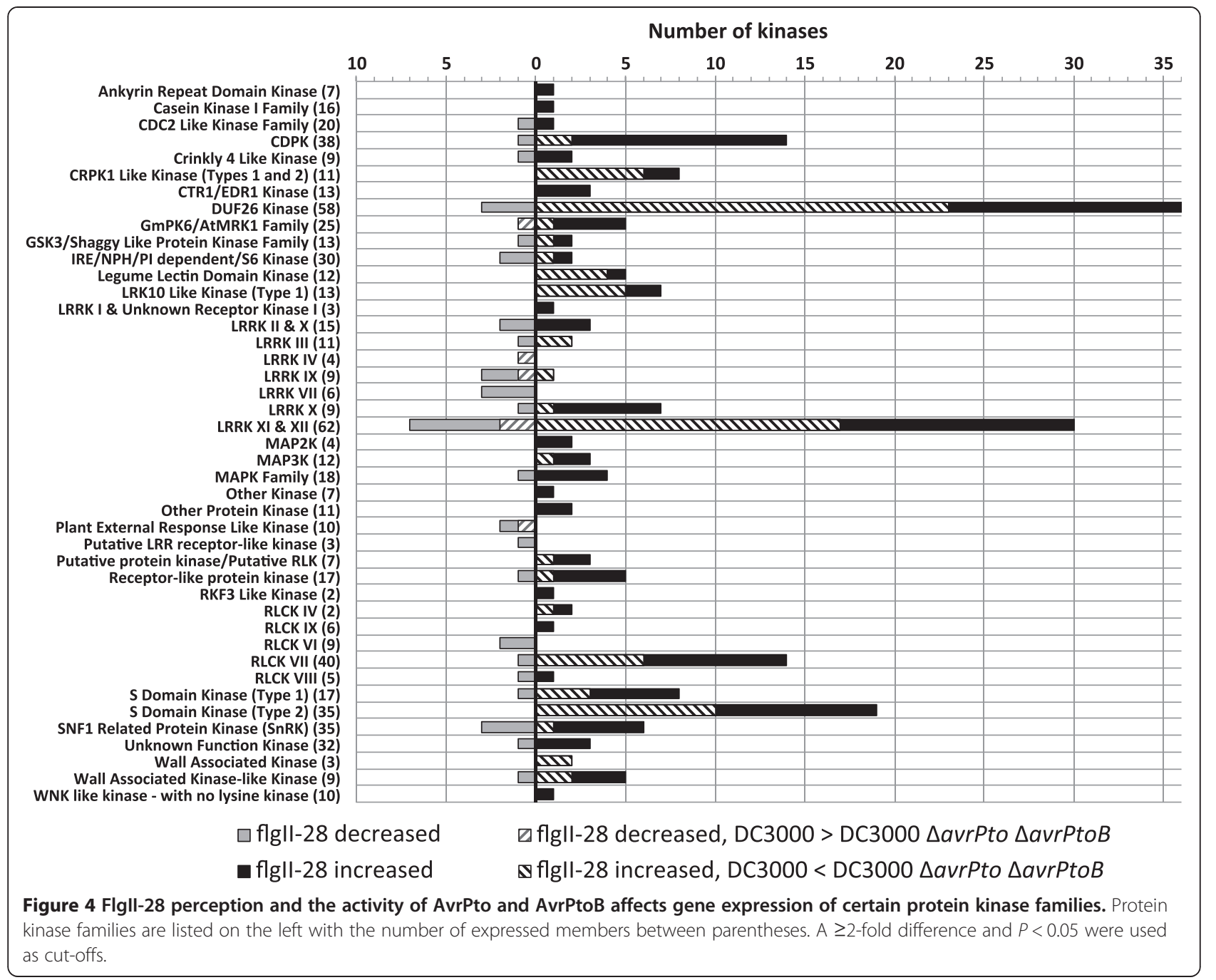

To examine the effect of SlWAK1 on immunity further, we initially performed disease assays using either vacuum infiltration or dip inoculation of the $N$. benthamiana pathogen DC3000 $\Delta h o p Q 1-1$ at $5 \times 10^{4} \mathrm{cfu} / \mathrm{mL}$ but we did not see any bacterial growth or disease symptom differences among EC1, FLS2- or SlWAK1-silenced plants. As an alternative, we first infiltrated plants with $P$. fluorescens at $2 \times 10^{7} \mathrm{cfu} / \mathrm{mL}$ to induce PTI and $6 \mathrm{~h}$ later infiltrated the plants with DC3000 $\Delta$ hopQ1-1 at $10^{5} \mathrm{cfu} / \mathrm{mL}$. Using these conditions, we detected reproducible and statistically significant $(P<0.01)$ higher bacterial growth in plants silenced for SlWAK1 compared with the EC1 controls (Figure 5B). In FLS2-silenced plants bacterial growth was intermediate between that of EC1 and SIWAK1 plants, particularly at 3 days after inoculation (dai), but not statistically different from EC1 control plants. Disease symptoms were initially observed at 2 dai, and became more apparent at 7 dai (Figure 5C). SlWAK1-silenced plants had leaf necrosis similar to FLS2-silenced plants and both had more disease symptoms compared to $E C 1$ control plants.
There are 7 SlWAK and 16 SlWAK-Like (SlWAKL) predicted genes in tomato [30]. SlWAK1 is a part of a clustered four-gene family; two of these are not expressed in our conditions (Solyc09g014710 and Solyc09g014730) and expression of the other was constitutive (Solyc09g014740). A phylogenetic analysis of the WAK and WAKL proteins from Arabidopsis, N. benthamiana and tomato (Figure 6) showed that, as expected, those from the solanaceous species cluster together. Although some orthologous relationships may be evident, the solanaceous WAKs and WAKLs are generally distinct from those in Arabidopsis. Interestingly, Solyc09g015230 and Solyc09g015240, the tomato WAKs that are most closely related to the well-studied Arabidopsis WAK genes [31], are not expressed in tomato leaves. SIWAK1 clusters with several $N$. benthamiana and tomato proteins distinct from the Arabidopsis WAK proteins, suggesting the WAKs in these solanaceous species do not have a clear orthology to any of the Arabidopsis WAKs.

We took advantage of the draft genome sequence of $N$. benthamiana [32] and a phylogenetic analysis based 

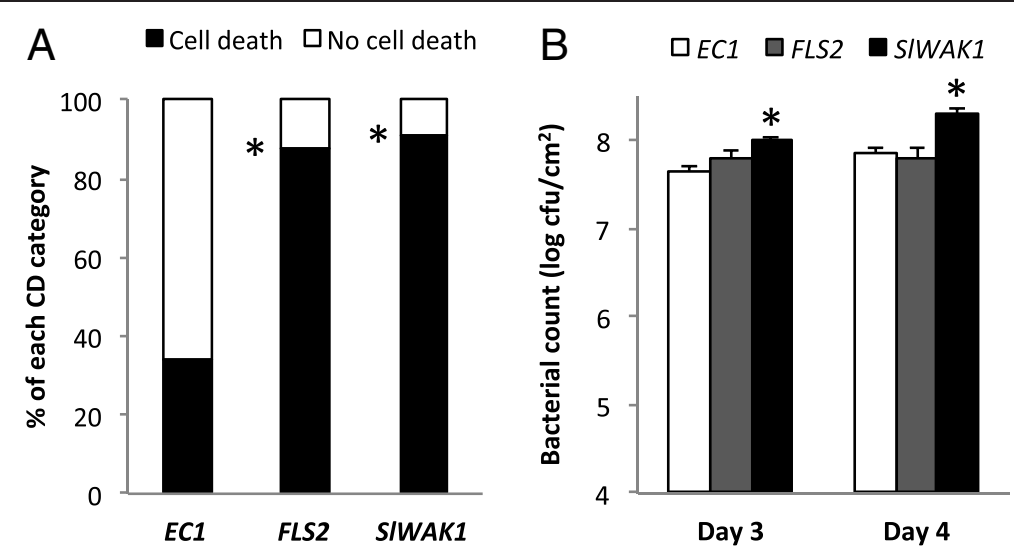

C

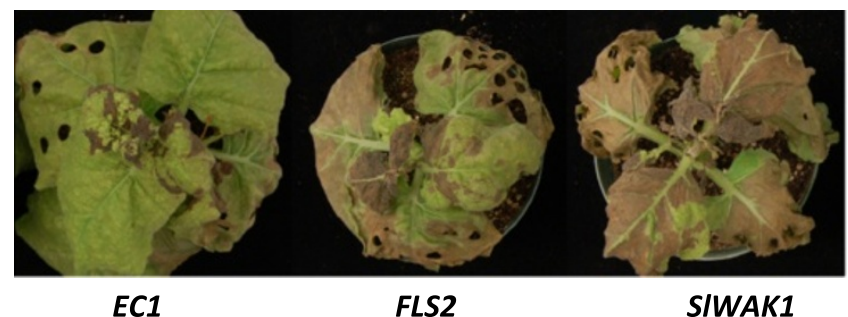

D

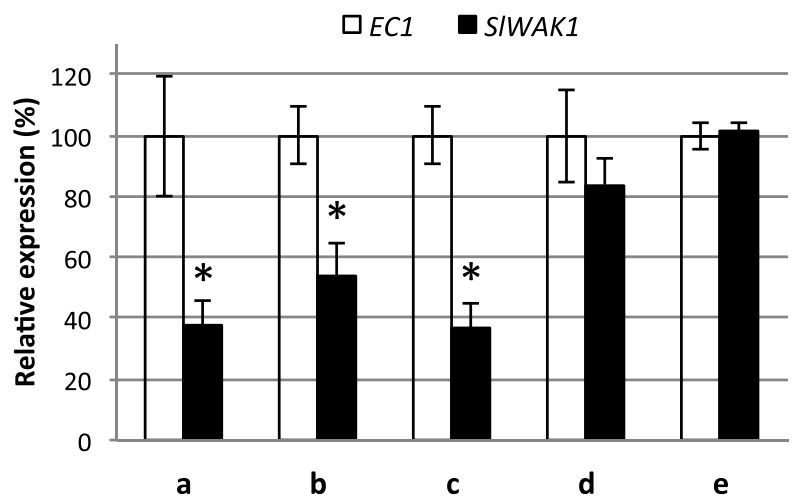

Figure 5 VIGS silencing of SIWAK1 in Nicotiana benthamiana results in compromised PTI and increased susceptibility to Pst. (A) Cell death suppression assay. Silenced plants were induced by syringe infiltration of Pseudomonas fluorescens and challenged $8 \mathrm{~h}$ later with DC3000 in an overlapping area. Cell death symptoms were scored in the overlapping area, on four independently silenced plants with four infiltration sites on two different leaves. Results shown are from 7 days after infiltration (dai). Asterisks indicate significant differences based on Dunnett's method, using $E C 1$ as a control $(P<0.01)$. (B) Pst growth in leaves. Silenced plants were vacuum-infiltrated with $P$. fluorescens, inoculated $6 \mathrm{~h}$ later with DC3000 $\Delta$ hopQ1-1 and sampled to measure bacterial populations. Results shown are the average of six plants per construct with the standard error. Asterisks indicate significant differences based on Dunnett's method, using EC1 as a control $(P<0.01)$. (C) Disease symptoms of plants treated as described in (B) 7 dai. (D) Silencing efficiencies in EC1 and SIWAK1 silenced plants assessed by qRT-PCR. Silencing efficiency is shown as relative expression compared to the EC1 control. Data were generated using EFla as reference gene and similar results were obtained using PP2A. Data from putative targets: (a) NbS00011055g0005.1, (b) NbS00011055g0014.1 and (c) NbS00011055g0002.1, and a predicted non-target (d) NbS00016938g0011.1 are shown. PP2A (e) was used as a cDNA integrity control. Asterisks indicate significant differences using a Student's $t$-test $(P<0.01)$. dai, days after infiltration; qRT-PCR, quantitative reverse transcription-PCR; Pst, Pseudomonas syringae pv. tomato; PTI, pattern-triggered immunity; VIGS, virus-induced gene silencing.

on nucleotide sequences to identify putative orthologs and possible off-targets of the SlWAK1 VIGS fragment using stringent conditions (that is, genes with $\geq 17 \mathrm{nu}$ cleotides of $100 \%$ identity). Additionally, we generated an RNA-seq dataset from $N$. benthamiana leaves infiltrated with $P$. fluorescens 55 at $10^{8} \mathrm{cfu} / \mathrm{mL}$, which we used to remove genes with low or no detectable transcripts from this analysis (<3 RPKM; Additional file 8: Table S4). This approach showed that our VIGS construct was predicted to silence three closely related WAK genes in $N$. benthamiana 


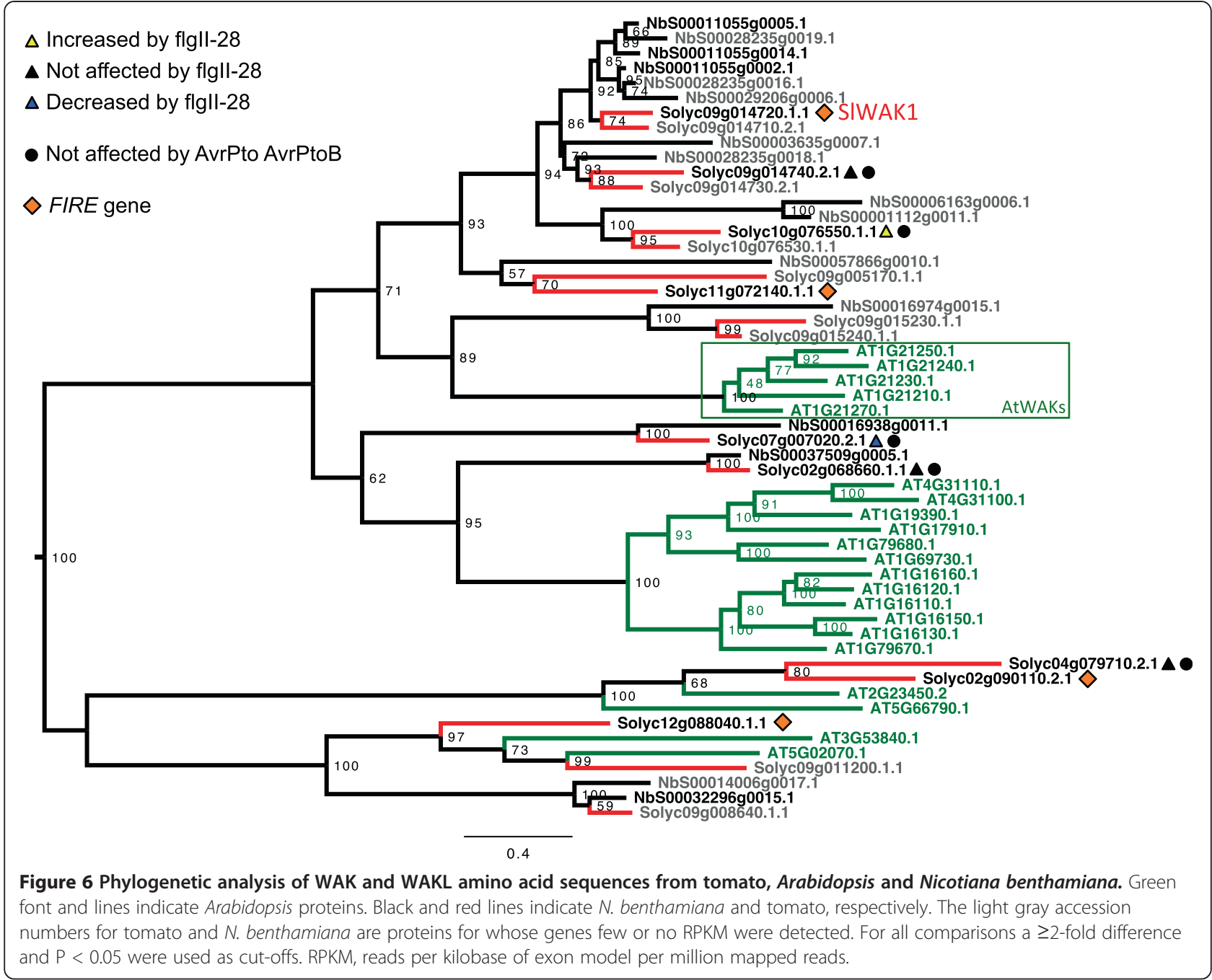

(Additional file 9: Table S5). Quantification of the transcript abundance of these genes by quantitative reverse transcription-PCR (qRT-PCR) supported this prediction as NbS00011055g0005, NbS00011055g0014 and NbS00011055g0002 each had decreased transcript abundance, ranging between $45 \%$ and $65 \%$, in plants silenced using SlWAK1 (Figure 5D). We chose one of the closest expressed predicted non-target genes (NbS00016938g0011, Additional file 10: Figure S5) and saw no difference in transcript abundance in SlWAK1-silenced plants (Figure 5D). Thus the increased susceptibility to Pst that we observe in SlWAK1-silenced plants may be due to either one or a combination of three SlWAK1 orthologs in N. benthamiana but is unlikely to be due to off-target silencing.

\section{Discussion}

We observed that about 13\% of the genes expressed in leaves under our conditions were induced $6 \mathrm{~h}$ after exposure to a single flagellin-derived MAMP. We hypothesized that Pseudomonas syringae pv. tomato (Pst) has evolved to interfere with many of the most important PTI-induced genes and so further focused on those genes whose expression is suppressed by two pathogen effector proteins, AvrPto and AvrPtoB. These effectors target PRR complexes as part of their virulence activity and are expected to compromise a large portion of the PTI response emanating from subsequent signaling events [14]. Of the 2,268 flgII-28induced genes, $27 \%$ were present in this flagellin-induced, repressed by effector (FIRE) class. At least 25 FIRE genes have been previously implicated in the plant immune response including Bti9 (Solyc02g079600), FLS2 (Solyc02g070890 and Solyc02g070910), RIN4 (Solyc09g059430 and Solyc06g083390), HvCRK1 (Solyc03g111540) and LCERKVI.2 (Solyc09g005000) (Additional file 5: Table S2). From an initial screen of 33 protein kinase-encoding FIRE genes, we identified $S l W A K 1$, a gene that, when silenced, compromised the host immune response to Pst infection to a similar degree as that observed in FLS2-silenced plants. 
Together, the collection of 622 FIRE genes provides a new resource for functional genomics screens in solanaceous plants and for comparative transcriptomics of PTI and ETI responses induced by specific MAMPs and DAMPs and diverse pathogens.

Plants recognize several bacterial MAMPs including flg22, EF-Tu, csp22, peptidoglycan and lipopolysaccharides, although the importance of each of these in any particular plant species varies [4]. Recently, a new flagellinderived MAMP, flgII-28, has been discovered that is recognized by tomato and other solanaceous plants but not by Arabidopsis [12]. The possibility that FLS2 might be involved in flgII-28 recognition has been excluded and its receptor remains unknown [13]. Here we used flgII-28 to elicit PTI in tomato leaves and found that it induces large transcriptional changes similar to host responses to other MAMPs. These changes largely overlap with those observed when the FliC protein is used to elicit PTI as shown by comparisons of wild-type and flagellindeficient bacteria. Together, our RNA-seq experiments indicate that flagellin-derived MAMPs (flg22 and/or flgII28) are by the far the major bacterial MAMP recognized by tomato $6 \mathrm{~h}$ post inoculation. We cannot exclude the possibility that other MAMPs play an important role at other time points, in specific plant tissues or at certain stages of pathogen attack. For example, we have reported that the Bti9 kinase (the AtCERK1 ortholog in tomato) likely detects a flagellin-independent MAMP and makes an important contribution to Pst resistance, especially in the lower leaves of tomato [16]. It also has been discovered that in Arabidopsis seedlings the transcriptional response to oligogalacturonides (OGs) and flg22 greatly overlaps $1 \mathrm{~h}$ after exposure, but at $3 \mathrm{~h}$ the flg22 transcriptional response is still high while the response to OGs is diminished, suggesting that transcriptional reprogramming due to perception of these two elicitors changes over time [23]. Further experiments with additional MAMPs and at multiple time points will be needed to understand better possible temporal effects on the host response to bacterial elicitors.

The central importance of flagellin detection in the activation of the PTI response in tomato makes it a vulnerable target for bacterial pathogens. Currently, five Pst effectors are known to undermine the FLS2-BAK1 pathway (AvrPto, AvrPtoB, AvrPphB, HopAI1 and HopF2) [6]. Examination of a 'minimal repertoire' of type III effectors needed to confer full virulence to Pst strain DC3000 revealed that AvrPto and AvrPtoB are 'early acting' effectors whose activity allows for the manipulation by later acting effectors of other host defenses such as vesicle trafficking [5]. This early activity is due to the fact that AvrPto and AvrPtoB each have a domain that binds and inhibits the kinase domains of proteins in the FLS2/BAK1 complex [14]. Our finding that about $30 \%$ of the genes induced by flgII- 28 are suppressed by AvrPto and/or AvrPtoB suggests they may also disrupt the flgII-28 receptor complex. Each of these effectors also has other domains with virulence-promoting activities [15,16,33-35]. Whether these domains affect host gene expression is unknown, but our present RNA-seq data suggest that transcriptomics combined with point mutations in each effector, which affect the virulence determinants independently, could help elucidate the contributions of each domain.

Our initial VIGS screen of 33 kinase-encoding FIRE genes identified a plant cell wall-associated kinase (SlWAK1) that plays an important role in resistance to infection by Pst. WAK genes were first identified in Arabidopsis where they occur as a clustered five-member gene family along with 21 other 'WAK-like kinases' (WAKL) elsewhere in the genome $[31,36,37]$. WAK and most WAKL proteins contain a cytoplasmic kinase domain, a transmembrane domain and extracellular epidermal growth factor motifs [37]. These proteins have been implicated previously in host responses to pathogen attack and particularly in the perception of pectin-derived fragments [31]. WAKLs were found to be highly represented among the kinases induced by MAMPs in Arabidopsis although no specific gene was shown to contribute to the immune response [22]. In fact, a clear demonstration of the role of WAKs in host defense by loss-of-function analyses has been hindered by lethality or developmental defects of some WAK mutants and possibly redundancy, which is not easily addressed by a mutational approach, due to the tight linkage of the five WAK genes in Arabidopsis [38]. As a result, the best evidence to date that WAKs play a role in immunity comes from indirect approaches. For example, overexpression of chimeric receptors using domains of WAK1 and EFR revealed that WAK1 is a receptor for OGs and can contribute to resistance to Agrobacterium tumefaciens and Botrytis cinerea [39]. In another study, a dominant allele of $W A K 2$, which was created by fusing it to an artificial epitope tag, induced various defense-associated responses that were suppressed by a mpk6 mutation [40]. In addition, certain WAKLs have been implicated in resistance to fungal pathogens $[41,42]$ and recently AtWAKL10 was reported to be expressed coordinately with defense-related genes [43].

In our case, silencing reduced the transcript abundance of three closely-related WAK genes in N. benthamiana by $45 \%$ to $65 \%$ and resulted in severely compromised PTI and enhanced susceptibility to Pst infection. There are seven predicted WAK genes in tomato and four of them occur in a clustered gene family that includes SlWAK1. Unlike genes belonging to the WAK family in Arabidopsis [23], SlWAK1 gene expression is induced during the response to MAMPs. Extensive sequence divergence prevented the assignment of orthologous relations between the tomato WAK genes and those in Arabidopsis. Consequently, we designated our gene as SlWAK1, since it appears to be the first WAK gene to 
be described in tomato. The previously reported LeWAK (Solyc02g090110) [44], is actually a WAKL and is most closely related to Arabidopsis WAKL14 (AT2G23450) and WAKL21 (AT5G66790) (Figure 6). LeWAK is also a FIRE gene and we silenced it along with two other FIRE WAK/L genes but observed no effect on PTI.

Based on previous work with Arabidopsis, it is possible that SIWAK1 acts as a DAMP receptor by playing a role in recognition of OGs and subsequent signal transduction. OGs could be generated from enzymatic activity encoded by either the pathogen or the host [45]. For example, DC3000 has both a pectin lyase (PL) and a polygalacturonase (PG), which could generate OGs during the infection process [46]. In addition, tomato has a $P G$ gene that was shown to be induced in leaves by damage (Solyc08g060970) and, interestingly, this is a FIRE gene. Another FIRE gene, Solyc05g005570, is closely related to a gene encoding a PG beta subunit that modulates PG activity (Solyc05g005560). Inhibitors of PG activity have been implicated in contributing to the formation of pectin fragments that function as DAMPs [3,45]. A gene encoding one of these inhibitors is induced by flagellin, but is not a FIRE gene (Solyc07g065090). Collectively, our observations support a model in which tomato recognition of MAMPs leads to increased expression of SlWAK1 and an increase in SIWAK1 receptors at the plasma membrane. Subsequently, OGs are generated by pathogen- and/or host-encoded enzymes and are recognized as DAMPs by SIWAK1, triggering a sustained immune response. Further experiments are needed to test this model, such as assaying whether SIWAK1 participates in OG perception, developing and testing DC3000 mutants that lack the $P L$ and/or $P G$ genes, and examining the effect of silencing the host $P G$ and $P G$ beta subunit genes.

Forward and reverse genetic screens for genes that act downstream of MAMP recognition have identified relatively few genes $[2,29]$. Instead, downstream components have mostly been discovered by biochemical (BAK1) or transcriptomic (BIK1) approaches [47,48]. This apparent shortcoming of genetic screens may be due to functional redundancy of specific genes or of PTI-induced pathways. It is also possible that, as with BAK1, many PTI-related genes play an important role in development or other fundamental processes and these genes might be missed by forward genetic screens. Here, we excluded from our VIGS screen those genes that have already been shown to be involved in immunity ( 25 out of 622 ). The fact that just one gene in the first 33 tested genes had a compromised immune response might indicate that relatively few PTI-induced genes play a critical role in immunity. Alternatively, this low frequency could be due to the use of heterologous fragments for VIGS silencing, limitations of the one PTI assay we used or redundancy in gene function. Consistent with the last possibility, multiple calcium-dependent protein kinases had to be knocked out to observe their involvement in immunity [49]. An initial challenge for such combinatorial genetic approaches to functional testing of redundant factors is the identification of a set of candidate genes that is small enough to be manageable and sufficiently documented to justify the effort. The FIRE genes we have identified here meet these criteria. Furthermore, our transcriptomic and phenotypic analyses of FIRE genes suggest that tomato defense against Pst is dominated by perception of a single MAMP and one or more DAMPs. Importantly, the FIRE gene set provides a new tool for unraveling the redundancies in downstream kinase signaling that are predicted to confer system robustness in the face of pathogen effector attack.

\section{Conclusions}

We performed an extensive RNA-seq analysis and VIGS screen to identify novel genes contributing to the plant immune response. The host response to flgII-28 and various bacterial strains indicated that flagellin is by far the major MAMP recognized by tomato. A Pseudomonas syringae mutant lacking two early acting effectors (AvrPto and AvrPtoB) allowed the identification of a defined set of FIRE genes. Among these FIRE genes, 25 have been previously implicated in plant defense highlighting the relevance of this 'pathogen-defined' set of genes. A wallassociated kinase was identified, which, when silenced, compromised the plant immune response to bacterial infection. The FIRE genes provide a unique resource for dissection of the plant immune system.

\section{Materials and methods}

\section{Bacterial strains and growth conditions}

Bacterial strains used in this work are listed in Additional file 11: Table S6. Pseudomonas strains were grown on King's B medium at $30^{\circ} \mathrm{C}$. Agrobacterium tumefaciens and E. coli were grown on Luria-Bertani (LB) medium at $30^{\circ} \mathrm{C}$ and $37^{\circ} \mathrm{C}$, respectively. Antibiotics used were: ampicillin $(100 \mu \mathrm{g} / \mathrm{mL})$, kanamycin $(50 \mu \mathrm{g} / \mathrm{mL})$, rifampicin $(10 \mu \mathrm{g} / \mathrm{mL})$ and spectinomycin $(50 \mu \mathrm{g} / \mathrm{mL})$.

\section{Plant material and treatments}

Plants were grown at $75 \%$ humidity with 16 h light (day $24^{\circ} \mathrm{C}$, night $22^{\circ} \mathrm{C}$ ). Four leaflets of the third true leaf of 4-week-old Rio Grande prf3 tomato plants were syringe-infiltrated and kept at $24^{\circ} \mathrm{C}$ and $75 \%$ humidity during the experiment. Infiltrations consisted of $1 \mu \mathrm{M}$ flgII-28 (ESTNILQRMRELAVQSRNDSNSSTDRDA, EZBiolab; 90\% purity) or bacterial strains (Table 1). Nicotiana benthamiana leaves were vacuum-infiltrated with Pseudomonas fluorescens 55 (P. fluorescens) at $10^{8} \mathrm{cfu} / \mathrm{mL}$ and sampled $6 \mathrm{~h}$ later. Mock-treated and untreated tissues were also collected. Three biological replicates (successive weekly treatments) were performed for each 
treatment. Tissue was collected at $6 \mathrm{~h}$ after infiltration, immediately frozen in liquid $\mathrm{N}_{2}$ and stored at $-80^{\circ} \mathrm{C}$ until used.

\section{RNA sequencing analysis}

Total RNA was isolated using TRIzol reagent (Life Technologies, Grand Island, NY, USA) and libraries for sequencing were constructed as described [50]. Barcoded libraries were multiplexed by eight in each lane and sequenced on an Illumina Hiseq 2000 system using the single-end mode. The length of the reads was 45 or $50 \mathrm{bp}$. Sequence reads have been deposited in the National Center for Biotechnology Information sequence read archive under accession number SRA096750. RNA-seq reads were first aligned to a ribosomal RNA sequence database [51] using Bowtie [52] and the aligned read sequences were removed. The remaining reads were aligned to the tomato genome sequence (version 2.40) using TopHat [53]. Detailed information on the quality of reads in each replicate is provided in Additional file 12: Table S7. Following alignment, for each gene model, the count of mapped reads from each sample was derived and normalized to RPKM (reads per kilobase of exon model per million mapped reads). Differentially expressed genes were identified using the DESeq 1.8 .3 package [54] with the raw count data. Raw $P$ values were corrected for multiple testing using the false discovery rate [55].

For $20 \%$ of the genes, we detected 0 RPKM indicating these are probably not expressed (or expressed at very low levels) in overall leaf tissue in our experimental conditions. In a eukaryotic cell with 200,000 mRNA molecules, 5 RPKM represents one detected mRNA per cell. Leaf tissue is a mixture of different cell populations, and the RPKM of a highly expressed but cell-specific gene could be masked by the scarcity of the cell type. Hence, there is no consensus on how to select and remove from the analysis poorly expressed genes, although cut-offs ranging from 0.3 to 10 RPKM are found in the literature $[56,57]$. In our case, to set a meaningful RPKM level, we examined the RPKM of a subset of genes known to play a role in plant immunity, including FLS2 (AT5G046330; Solyc02g070890 and Solyc02g070910), Rin4 (AT3G25070, Solyc06g083390 and Solyc09g059430), SISERK3A (AT4G33430, Solyc10g047140) and Bti9 (Solyc02g079600). Of these genes, FLS2.2 (Solyc02g070910) had the lowest values ranging from 0.12 to 6.45 RPKM with 3 RPKM in the $P$. fluorescens treatment (Additional file 1: Figure S1). Based on this information we included in our analysis genes with $\geq 3$ RPKM in at least one treatment (approximately 39 reads mapped per kilobase of transcript for an average of 13 million mapped reads; Additional file 12: Table S7).

\section{Virus-induced gene silencing}

For silencing, inserts of 300 to $400 \mathrm{bp}$ were chosen based on a BLAST analysis of the $N$. benthamiana genome sequence [58]. Primers were designed using Primer3 [59].
PCR amplification was performed using cDNA from Rio Grande prf3 tomato leaves treated with flgII-28 $(1 \mu \mathrm{M}$ for 6 h; EZ Biolabs, Carmel, IN, USA) or $N$. benthamiana leaves treated with flg22 (1 $\mu \mathrm{M}$ for $6 \mathrm{~h}$, GenScript, Piscataway, NJ, USA). PCR products were cloned into pCR8/GW/TOPO (Life Technologies) and recombined into a Gateway-compatible TRV2 vector [60]. After sequence confirmation, constructs were transformed into A. tumefaciens GV2260. VIGS in N. benthamiana plants was performed as described [61]. An FLS2 fragment and an E. coli gene-based fragment ( $E C 1$, which contains a $56 \% \mathrm{GC}$ content and not a single $\geq 17$ bp-long $100 \%$ identical stretch in $N$. benthamiana) were used as positive and negative controls. The DNA sequence of the fragments used were:

\section{$>E C 1$ (Escherichia coli fragment)}

CGGCGTGATTGCGCAAAGCTATCATCAGTCTGAG AAATCGGCCTCCGAGTTCGATGCCATTGTTGCGC AAACGGAGCAGTTCCTTGCCGACAATGGTCGTCG CCCGCGCATTCTGATCGCTAAGATGGGCCAGGAT GGACACGATCGCGGCGCGAAAGTGATCGCCAGC GCCTATTCCGATCTCGGTTTCGACGTAGATTTAA GCCCGATGTTCTCTACACCTGAAGAGATCGCCCG CCTGGCCGTAGAAAACGACGTTCACGTAGTGGGC GCATCCTCACTGGCTGCCGGTCATAAAACGCTGA TCCCGGAACTGGTCGAAGCGCTGAAAAAATGGG GACGCGAAGATATCTGCGTGGTCGCGGGTGGCG TCATTCCGCCGCAGGATTACGCCTTCCTGCAAGA GCGCGGCGTGGCGGCGATTTATGGTCCAGGTAC ACCTATGCTCGACAGTGTGCGCGACGTACTGAA TCTGATAAGCCAGCATCATGATTAATGAAGCCACG CTGGCAGAAAGTATTCG

\section{>Tomato FLS2.1 (Solyc02g070890)}

AAAGTGTACCGCAGCACTGAGCCTCCAGAGATTT TATCAAAAGGATTTGGAACATGCTACCAATAATT TCCGTCCGGAAAACATTATTGGAGCCAGCAGTTT AAGTACTGTGTACAAAGGAACACTGGAAGATGG GAAGATTGTAGCAGTTAAGAAGCTGAATCACCAG TTCTCAGCAGAATCTGGTAAATGTTTTGATAGGG AAGTCAAGACTCTGAGCCAACTCAGACACAGGA ACCTAGTTAAGGTGCTAGGTTACGCTTGGGAAAG CAAGAAGCTAAGGGCTTTAGTTTTAGAATACATG GAGAATGGGAACTTGGACAACATGATTTATGGTC AAGTAGAGGATGACTGGACGTTGTCCAACAGGAT TGATATTTTAGTTTCAGTTGCAAGTGGACTATCA TACCTGCATTCAGGCTATGATTTTCCAATAGTGC ACTGTGACATGAAGCCTTCAAACATTCTTCTGGA CAAAAATATGGAAGCACATGTGAGTGACTTTGGG ACGGCTAGGATGTTGGGTATTCA

\section{>SIWAK1 (Solyc09g014720)}

AGGCTACAAACAACTATGCCAGTGATAGAATTCT TGGTCGTGGTGGAAATGGAATTGTCTACAAAGGC 
ATTCTATCTGATAATCGCATAGTTGCTATTAAGAA ATCTAAGTTTATGGACGAGGAACAGGTTGAACAG TTCATTAACGAGGTACTTATTCTTACTCAAGTCA ACCATAGAAATGTTGTGAGACTCTTCGGATGTTG TTTGGAAGCCGAAGTTCCTTTACTTGTCTATGAA TACATTTCTCATGGAACTCTTTACGAGCATATCCA CAATCGAAATGGAGCACCTTGGTTATCTTGGGAA AATCGGCTAAGAGTTGCTAGTGAGACAGCAAGT GCACTTGCTTACCTTCATTCATCCGCGCAAATGC CTATAATTCATAGAGATGTCAAGTCTGCCAATTTA TTGTTGGA

\section{Cell death suppression assay (pattern-triggered immunity assay)}

VIGS plants were tested for compromised PTI as described [29], with minor modifications. Leaves were induced by syringe infiltration with $P$. fluorescens 55 at $\mathrm{OD}_{600}=0.5$ and $8 \mathrm{~h}$ later challenged, in a partially overlapping region, with DC3000 at $\mathrm{OD}_{600}=0.01$. The appearance of cell death (CD) in the overlapping area was scored at day 7, using the categories: PTI breakdown ( $>50 \%$ of overlapping area with CD), and no PTI breakdown (<50\%). In each experiment, four plants per construct were used with eight overlapping infiltrations each. Each experiment was repeated at least three times. Significant differences are based on Dunnett's method, using TRV:EC1 plants as controls $(P<0.01)$.

\section{Bacterial growth assays}

Seven-week-old silenced plants were vacuum-infiltrated with a suspension of $P$. fluorescens $55\left(2 \times 10^{7} \mathrm{cfu} / \mathrm{mL}\right)$ in $10 \mathrm{mM} \mathrm{MgCl}_{2}$ and $0.002 \%$ Silwet L-77 (Comptom Co). Plants were kept at $24^{\circ} \mathrm{C}$ and $75 \%$ humidity for $6 \mathrm{~h}$ and then vacuum-infiltrated with DC3000 4 hopQ1-1 $\left(10^{5} \mathrm{cfu} / \mathrm{mL}\right)$ suspended in the same solution. To measure bacterial populations, three $0.43 \mathrm{~cm}^{2}$ disks were taken from the oldest expanding leaves and processed twice in a Tissue Lyser (Qiagen) for $30 \mathrm{sec}$ at $25 / \mathrm{sec}$ frequency with $0.25 \mathrm{~mL}$ of $10 \mathrm{mM} \mathrm{MgCl}_{2}$. The volume was adjusted to $1 \mathrm{~mL}$ and serial dilutions were plated on solid LB medium with antibiotics. In each experiment, six biological replicates per construct were used. Significant differences are based on Dunnett's method, using TRV: EC1 plants as controls $(P<0.01)$.

\section{Gene and treatment clustering and gene ontology term analysis}

Genes with an expression value of $\geq 3 \mathrm{RPKM}$ in at least one treatment and a maximum/minimum ratio $\geq 3$ across all treatments were used for clustering. Hierarchical clustering was performed using Cluster 3.0 [62] with the average linkage clustering method and the Pearson correlation as the measure of similarity. GO term enrichment analysis was based on the GO::TermFinder module [63].

\section{Phylogenetic analysis and degree of overlap between bacterial strains and flgll-28 treatment}

A substitution model was evaluated using JModelTest $[64,65]$ for nucleotide sequences and ProtTest [66] for proteins. PhyML through SeaView [67] was used to perform the analysis with the default parameters for the GTR model (nucleotides) and the JTT model (proteins). One hundred bootstraps were used for each analysis. A tree figure was created using FigTree [68]. Venny [69] was used to generate Venn diagrams to study the degree of overlap between genes affected by flgII-28 and different bacterial strains treatments.

\section{Identification of FIRE immunity-associated genes}

A bibliographic search associated with the FIRE genes was performed through: (1) a SQL search of the Sol Genomic Network database [70] using the Solyc identifiers in the Phenome and Chado schema that contains the manually curated loci and (2) a Swissprot database search of the Arabidopsis homologous genes (identified using the best match of a Selfblast search). The Swissprot database was mined using a Perl script (available upon request).

\section{Virus-induced gene silencing efficiency}

Six $N$. benthamiana silenced plants per construct were vacuum-infiltrated with $P$. fluorescens 55 as described above and samples taken at 5, 6, 7 and $8 \mathrm{~h}$ later. Tissues from the same plant were pooled and the resulting RNA used for quantitative reverse transcription-PCR (qRT-PCR). Total RNA was isolated using the Plant RNA isolation reagent (Life Technologies, Grand Island, NY, USA) according to the manufacturer's instructions. Then $6 \mu \mathrm{g}$ of total RNA was processed with the TURBO DNA-free kit (Life Technologies) for $60 \mathrm{~min}$ at $37^{\circ} \mathrm{C}$. After DNase treatment, $2 \mu \mathrm{g}$ RNA was used to prepare cDNA using the SuperScript III First-Strand Synthesis System (Life Technologies) with oligo(dT)20. qRT-PCR was performed as described previously [71]. The sequence of the primers used for each gene analyzed were: NbS00011055g0005.1 F 5'-GAAATATCCCACGGTGATCC-3', NbS00011055g 0005.1R 5'-GAAGAATGACTGCGGTTAGG-3'; NbS000 11055g0014.1 F 5'-CCCGTTACTCAATACGTTCTT-3', NbS00011055g0014.1R 5' -ATTGGGCGGTGGTTAATG-3'; NbS00011055g0002.1 F 5'-AACAATATCCCACGGTGAC$3^{\prime}$ and NbS00011055g0002.1R 5'-TTAAAGGAAGACGC GAAGG-3'. Cycling conditions during qRT-PCR were $50^{\circ} \mathrm{C}$ for $2 \mathrm{~min}, 95^{\circ} \mathrm{C}$ for $10 \mathrm{~min}$, and 40 cycles of $95^{\circ} \mathrm{C}$ for $30 \mathrm{~s}, 55^{\circ} \mathrm{C}$ for $30 \mathrm{~s}$ and $72^{\circ} \mathrm{C}$ for $30 \mathrm{~s}$. Data were normalized to the $N b P P 2 a$ and $N b E F 1 \alpha$ genes [72]. The significance of the expression data was analyzed using a pairwise Student's $t$-test $(P<0.01)$. 


\section{Additional files}

Additional file 1: Figure S1. Expression level of selected immunity-related genes used for establishing a minimum RPKM cut-off. Bars represent the average of three biological replicates with the corresponding standard error. Arrows highlight transcript abundance differences between wild type DC3000 and DC3000_avrPto_avrPtoB. FLS2.1 Solyc02g070890, FLS2.2 Solyc02g070910, Bti9 Solyc02g079600, SERK3A Solyc10g047140, RIN4.1 Solyc09g059430 and RIN4.2 Solyc06g083390.

Additional file 2: Figure S2. Amino acid sequences of the flgll-28 region in various bacterial strains. Asterisks indicate key residues shown to be important for the elicitation of reactive oxygen species production.

Additional file 3: Figure S3. Overlap between genes suppressed by bacterial strains and flgll-28 treatments. (A) Overlap between Pseudomonas syringae pv. tomato strains and flgll-28. (B) Overlap between soil Pseudomonas and flgll-28. (C) Degree of overlap shown as percentage of genes.

Additional file 4: Table S1. GO term analysis of genes belonging to clusters A and B (Figure 3). Terms are grouped based on process (P), component (C) and function ( $F$ ).

Additional file 5: Table S2. (A) Extracted FIRE gene expression data. (B) Additional immune-related FIRE genes identified using less stringent cut-offs. Comment and reference columns show information about genes previously shown to participate in plant immunity based on publications involving tomato and Arabidopsis (See Materials and methods for detailed information).

Additional file 6: Table S3. GO term analysis of FIRE genes using genes induced by flgll-28 as the reference. Terms are grouped based on process (P), component (C) and function (F).

Additional file 7: Figure S4. The growth and development of SIWAK1-silenced plants are not affected.

Additional file 8: Table S4. WAKLL RNA-seq gene expression analysis of $N$. benthamiana leaves sampled $6 \mathrm{~h}$ post vacuum infiltration with $P$. fluorescens 55. Data shown correspond to the average of three biological replicates per treatment. See Materials and methods for details.

Additional file 9: Table S5. SIWAK1 VIGS construct target analysis in $N$. benthamiana. The length of $100 \%$ match regions $\geq 17$ nucleotides long was determined by considering genes with $\geq 3$ RPKM in at least one condition,. Predicted non-target gene information is shown at the bottom of the Table. N.C., not considered due to low or no expression.

Additional file 10: Figure S5. Phylogenetic analysis of WAK and WAKL nucleotide sequences from $N$. benthamiana including SIWAK1, which was used to identify putative VIGS construct targets and off-targets. The PhyML method with a bootstrap of 100 replicates was used for the analysis. The bold black font indicates expressed genes with $\geq 3$ RPKM after either mock or $P$. fluorescens $\left(10^{8} \mathrm{cfu} / \mathrm{mL}\right)$ treatment. Color-coded squares show the effect of $P$. fluorescens infiltration using a $\geq 2$-fold difference and $P<0.05$ as cut-offs. The genes considered to be possible targets of the SIWAKI VIGS construct are in clusters $A$ and $B$ and are further described in Additional file 9: Table S5. The asterisk indicates the predicted VIGS non-target gene tested by qRT-PCR (Figure 5).

Additional file 11: Table S6. Details of the bacterial strains used in this study.

Additional file 12: Table S7. Summary of the sequencing data for each of the libraries generated in this work.

\section{Abbreviations}

bp: Base pair; CD: Cell death; CDSA: Cell death suppression assay; dai: Days after inoculation; DAMP: Damage-associated molecular pattern; ETI: Effector-triggered immunity; FIRE: Flagellin-induced repressed by effectors; GO: Gene ontology; LRR: Leucine-rich repeat; MAMP: Microbe-associated molecular pattern; OG: Oligogalacturonides; PCR: Polymerase chain reaction; PG: Polygalacturonase; PL: Pectin lyase; PRR: Pattern recognition receptor; Pst: Pseudomonas syringae pv. tomato; PTI: Pattern-triggered immunity; GRT-PCR: Quantitative reverse transcription-PCR; RNA-seq: RNA sequencing; RPKM: Reads per kilobase of exon model per million mapped reads; TF: Transcription factor; VIGS: Virus-induced gene silencing; WAK: Wall-associated kinase.

\section{Competing interests}

The authors declare that they have no competing interests.

\section{Authors' contributions}

HGR, ZF, AC and GBM designed the research. SZ contributed new reagents and analytic tools. HGR and MAP performed the research. HGR, YZ, MAP, AB, ZF and GBM analyzed the data. HGR and GBM wrote the paper. All authors read and approved the final manuscript.

\section{Acknowledgments}

We thank Diane Dunham, Brandon Maziuk and Paige Reeves for their assistance in the greenhouse and Sarah Hind, Patrick Boyle and Johannes Mathieu for helpful comments on the manuscript. This research was supported by National Science Foundation grants IOS-0841807 (GBM) and IOS-1025642 (AC, GBM).

\section{Author details}

'Boyce Thompson Institute for Plant Research, Ithaca, NY 14853, USA. ${ }^{2}$ Instituto de Investigaciones Biotecnológicas - Instituto Tecnológico de Chascomús (IIB-INTECH) UNSAM-CONICET, Chascomús B7130IWA, Buenos Aires, Argentina. ${ }^{3}$ School of Life Sciences, The Chinese University of Hong Kong, NT, Hong Kong. ${ }^{4}$ Department of Plant Pathology and Plant-Microbe Biology, Cornell University, Ithaca, NY 14853, USA. ${ }^{5}$ Department of Biological Sciences, King Abdulaziz University, Jeddah 21589, Saudi Arabia.

Received: 5 September 2013 Accepted: 20 December 2013 Published: 20 December 2013

\section{References}

1. Dodds PN, Rathjen JP: Plant immunity: towards an integrated view of plant--pathogen interactions. Nat Rev Genet 2010, 11:539-548.

2. Schwessinger B, Ronald PC: Plant innate immunity: perception of conserved microbial signatures. Annu Rev Plant Biol 2012, 63:451-482.

3. Nuhse TS: Cell wall integrity signaling and innate immunity in plants. Front Plant Sci 2012, 3:280.

4. Segonzac C, Zipfel C: Activation of plant pattern-recognition receptors by bacteria. Curr Opin Microbiol 2011, 14:54-61.

5. Lindeberg M, Cunnac S, Collmer A: Pseudomonas syringae type III effector repertoires: last words in endless arguments. Trends Microbiol 2012, 20:199-208.

6. Xin XF, He SY: Pseudomonas syringae pv. tomato DC3000: a model pathogen for probing disease susceptibility and hormone signaling in plants. Annu Rev Phytopathol 2013, 51:473-498.

7. Melotto M, Underwood W, He SY: Role of stomata in plant innate immunity and foliar bacterial diseases. Annu Rev Phytopathol 2008, 46:101-122.

8. Gomez-Gomez L, Boller T: FLS2: an LRR receptor-like kinase involved in the perception of the bacterial elicitor flagellin in Arabidopsis. Mol Cell 2000, 5:1003-1011

9. Chinchilla D, Zipfel C, Robatzek S, Kemmerling B, Nurnberger T, Jones JD, Felix G, Boller T: A flagellin-induced complex of the receptor FLS2 and BAK1 initiates plant defence. Nature 2007, 448:497-500.

10. Zhang J, Li W, Xiang T, Liu Z, Laluk K, Ding X, Zou Y, Gao M, Zhang X, Chen $S$, Mengiste T, Zhang Y, Zhou JM: Receptor-like cytoplasmic kinases integrate signaling from multiple plant immune receptors and are targeted by a Pseudomonas syringae effector. Cell Host Microbe 2010 7:290-301.

11. Lu D, Wu S, Gao X, Zhang Y, Shan L, He P: A receptor-like cytoplasmic kinase, BIK1, associates with a flagellin receptor complex to initiate plant innate immunity. Proc Natl Acad Sci USA 2010, 107:496-501.

12. Cai R, Lewis J, Yan S, Liu H, Clarke CR, Campanile F, Almeida NF, Studholme $D$ J, Lindeberg M, Schneider D, Zaccardelli M, Setubal JC, Morales-Lizcano NP, Bernal A, Coaker G, Baker C, Bender CL, Leman S, Vinatzer BA: The plant pathogen Pseudomonas syringae pv. tomato is genetically monomorphic and under strong selection to evade tomato immunity. PLoS Pathog 2011, 7:e1002130.

13. Clarke $C R$, Chinchilla D, Hind SR, Taguchi F, Miki R, Ichinose $Y$, Martin GB, Leman S, Felix G, Vinatzer BA: Allelic variation in two distinct Pseudomonas syringae flagellin epitopes modulates the strength of plant immune responses but not bacterial motility. New Phytol 2013, 200:847-860. 
14. Martin GB: Suppression and activation of the plant immune system by Pseudomonas syringae effectors AvrPto and AvrPtoB. In Effectors in Plant-Microbe Interactions. Edited by Martin F, Kamoun S. London: Wiley-Blackwell, John Wiley and Sons; 2012:123-154.

15. Yeam I, Nguyen HP, Martin GB: Phosphorylation of the Pseudomonas syringae effector AvrPto is required for FLS2/BAK1-independent virulence activity and recognition by tobacco. Plant J 2010, 61:16-24.

16. Zeng L, Velasquez AC, Munkvold KR, Zhang J, Martin GB: A tomato LysM receptor-like kinase promotes immunity and its kinase activity is inhibited by AvrPtoB. Plant J 2012, 69:92-103.

17. Pedley KF, Martin GB: Molecular basis of Pto-mediated resistance to bacterial speck disease in tomato. Annu Rev Phytopathol 2003, 41:215-243.

18. Zhao Y, Thilmony R, Bender CL, Schaller A, He SY, Howe GA: Virulence systems of Pseudomonas syringae pv. tomato promote bacterial speck disease in tomato by targeting the jasmonate signaling pathway. Plant J 2003, 36:485-499.

19. Zipfel C, Robatzek S, Navarro L, Oakeley EJ, Jones JDG, Felix G, Boller T: Bacterial disease resistance in Arabidopsis through flagellin perception. Nature 2004, 428:764-767.

20. Navarro L, Zipfel C, Rowland O, Keller I, Robatzek S, Boller T, Jones JD: The transcriptional innate immune response to flg22. Interplay and overlap with Avr gene-dependent defense responses and bacterial pathogenesis. Plant Physiol 2004, 135:1113-1128.

21. Truman W, de Zabala MT, Grant M: Type III effectors orchestrate a complex interplay between transcriptional networks to modify basal defence responses during pathogenesis and resistance. Plant J 2006, 46:14-33.

22. Thilmony R, Underwood W, He SY: Genome-wide transcriptional analysis of the Arabidopsis thaliana interaction with the plant pathogen Pseudomonas syringae pv. tomato DC3000 and the human pathogen Escherichia coli 0157:H7. Plant J 2006, 46:34-53.

23. Denoux C, Galletti R, Mammarella N, Gopalan S, Werck D, De Lorenzo G, Ferrari S, Ausubel FM, Dewdney J: Activation of defense response pathways by OGs and Flg22 elicitors in Arabidopsis seedlings. Mol Plant 2008, 1:423-445.

24. Mysore KS, Crasta OR, Tuori RP, Folkerts O, Swirsky PB, Martin GB: Comprehensive transcript profiling of Pto- and Prf-mediated host defense responses to infection by Pseudomonas syringae pv. tomato. Plant J 2002, 32:299-315.

25. de Torres M, Sanchez P, Fernandez-Delmond I, Grant M: Expression profiling of the host response to bacterial infection: the transition from basal to induced defence responses in RPM1-mediated resistance. Plant J 2003, 33:665-676.

26. Tomato Genome Consortium: The tomato genome sequence provides insights into fleshy fruit evolution. Nature 2012, 485:635-641.

27. Cunnac S, Chakravarthy S, Kvitko BH, Russell AB, Martin GB, Collmer A: Genetic disassembly and combinatorial reassembly identify a minimal functional repertoire of type III effectors in Pseudomonas syringae. Proc Natl Acad Sci USA 2011, 108:2975-2980.

28. Tomato functional genomics database. http://ted.bti.cornell.edu.

29. Chakravarthy S, Velasquez AC, Ekengren SK, Collmer A, Martin GB: Identification of Nicotiana benthamiana genes involved in pathogenassociated molecular pattern-triggered immunity. Mol Plant Microbe Interact 2010, 23:715-726.

30. ITAK - Plant Transcription factor and Protein Kinase Identifier and Classifier. http://bioinfo.bti.cornell.edu/cgi-bin/itak/index.cgi.

31. Kohorn BD, Kohorn SL: The cell wall-associated kinases, WAKs, as pectin receptors. Front Plant Sci 2012, 3:88

32. Bombarely A, Rosli HG, Vrebalov J, Moffett P, Mueller LA, Martin GB: A draft genome sequence of Nicotiana benthamiana to enhance molecular plant-microbe biology research. Mol Plant Microbe Interact 2012, 25:1523-1530

33. Xiao F, He P, Abramovitch RB, Dawson JE, Nicholson LK, Sheen J, Martin GB: The N-terminal region of Pseudomonas type III effector AvrPtoB elicits Pto-dependent immunity and has two distinct virulence determinants. Plant J 2007, 52:595-614.

34. Nguyen HP, Yeam I, Angot A, Martin GB: Two virulence determinants of type III effector AvrPto are functionally conserved in diverse Pseudomonas syringae pathovars. New Phytol 2010, 187:969-982.

35. Gimenez-lbanez S, Hann DR, Ntoukakis V, Petutschnig E, Lipka V, Rathjen JP: AvrPtoB targets the LysM receptor kinase CERK1 to promote bacterial virulence on plants. Curr Biol 2009, 19:423-429.
36. He ZH, Cheeseman I, He D, Kohorn BD: A cluster of five cell wall-associated receptor kinase genes, Wak1-5, are expressed in specific organs of Arabidopsis. Plant Mol Biol 1999, 39:1189-1196.

37. Verica JA, He ZH: The cell wall-associated kinase (WAK) and WAK-like kinase gene family. Plant Physiol 2002, 129:455-459.

38. De Lorenzo G, Brutus A, Savatin DV, Sicilia F, Cervone F: Engineering plant resistance by constructing chimeric receptors that recognize damageassociated molecular patterns (DAMPs). FEBS Lett 2011, 585:1521-1528.

39. Brutus A, Sicilia F, Macone A, Cervone F, De Lorenzo G: A domain swap approach reveals a role of the plant wall-associated kinase 1 (WAK1) as a receptor of oligogalacturonides. Proc Natl Acad Sci USA 2010, 107:9452-9457.

40. Kohorn BD, Kohorn SL, Todorova T, Baptiste G, Stansky K, McCullough M: A dominant allele of Arabidopsis pectin-binding wall-associated kinase induces a stress response suppressed by MPK6 but not MPK3 mutations. Mol Plant 2012, 5:841-851.

41. Diener AC, Ausubel FM: Resistance to Fusarium oxysporum 1, a dominant Arabidopsis disease-resistance gene, is not race specific. Genetics 2005, 171:305-321.

42. Li H, Zhou SY, Zhao WS, Su SC, Peng YL: A novel wall-associated receptorlike protein kinase gene, OsWAK1, plays important roles in rice blast disease resistance. Plant Mol Biol 2009, 69:337-346.

43. Meier S, Ruzvidzo O, Morse M, Donaldson L, Kwezi L, Gehring C: The Arabidopsis wall associated kinase-like 10 gene encodes a functional guanylyl cyclase and is co-expressed with pathogen defense related genes. PLoS One 2010, 5:e8904

44. Lejeune A, Constant S, Delavault P, Simier P, Thalouarn P, Thoiron S: Involvement of a putative Lycopersicon esculentum wall-associated kinase in the early steps of tomato-Orobanche ramosa interaction. Physiol Molec Plant Pathol 2006, 69:3-12.

45. Ferrari S, Savatin DV, Sicilia F, Gramegna G, Cervone F, Lorenzo GD: Oligogalacturonides: plant damage-associated molecular patterns and regulators of growth and development. Front Plant Sci 2013, 4:49.

46. Buell CR, Joardar V, Lindeberg M, Selengut J, Paulsen IT, Gwinn ML, Dodson RJ, Deboy RT, Durkin AS, Kolonay JF, Madupu R, Daugherty S, Brinkac L, Beanan MJ, Haft DH, Nelson WC, Davidsen T, Zafar N, Zhou L, Liu J, Yuan Q, Khouri H, Fedorova N, Tran B, Russell D, Berry K, Utterback T, Van Aken SE, Feldblyum TV, D'Ascenzo M, et al: The complete genome sequence of the Arabidopsis and tomato pathogen Pseudomonas syringae pv. tomato DC3000. Proc Natl Acad Sci USA 2003, 100:10181-10186.

47. Nam KH, Li J: BRI1/BAK1, a receptor kinase pair mediating brassinosteroid signaling. Cell 2002, 110:203-212.

48. Veronese P, Nakagami H, Bluhm B, Abuqamar S, Chen X, Salmeron J, Dietrich RA, Hirt H, Mengiste T: The membrane-anchored Botrytis-induced kinase 1 plays distinct roles in Arabidopsis resistance to necrotrophic and biotrophic pathogens. Plant Cell 2006, 18:257-273.

49. Boudsocq M, Willmann MR, McCormack M, Lee H, Shan L, He P, Bush J, Cheng SH, Sheen J: Differential innate immune signalling via $\mathrm{Ca}^{2+}$ sensor protein kinases. Nature 2010, 464:418-422.

50. Zhong S, Joung JG, Zheng Y, Chen YR, Liu B, Shao Y, Xiang JZ, Fei Z, Giovannoni JJ: High-throughput Illumina strand-specific RNA sequencing library preparation. Cold Spring Harb Protoc 2011, 2011:940-949.

51. Quast C, Pruesse E, Yilmaz P, Gerken J, Schweer T, Yarza P, Peplies J, Glockner FO: The SILVA ribosomal RNA gene database project: improved data processing and web-based tools. Nucleic Acids Res 2013, 41:D590-D596.

52. Langmead B, Trapnell C, Pop M, Salzberg SL: Ultrafast and memoryefficient alignment of short DNA sequences to the human genome. Genome Biol 2009, 10:R25.

53. Trapnell C, Pachter L, Salzberg SL: TopHat: discovering splice junctions with RNA-Seq. Bioinformatics 2009, 25:1105-1111.

54. Anders S, Huber W: Differential expression analysis for sequence count data. Genome Biol 2010, 11:R106.

55. Benjamini $Y$, Hochberg $Y$ : Controlling the false discovery rate: a practical and powerful approach to multiple testing. J Royal Stat Soc Series B (Methodological) 1995, 57:289-300.

56. Ramskold D, Wang ET, Burge CB, Sandberg R: An abundance of ubiquitously expressed genes revealed by tissue transcriptome sequence data. PLoS Comput Biol 2009, 5:e1000598.

57. Castruita M, Casero D, Karpowicz SJ, Kropat J, Vieler A, Hsieh SI, Yan W, Cokus S, Loo JA, Benning C, Pellegrini M, Merchant SS: Systems biology 
approach in Chlamydomonas reveals connections between copper nutrition and multiple metabolic steps. Plant Cell 2011, 23:1273-1292.

58. SOL genomics network. http://solgenomics.net/.

59. Rozen S, Skaletsky H: Primer3 on the WWW for general users and for biologist programmers. Methods Mol Biol 2000, 132:365-386.

60. Liu Y, Schiff M, Dinesh-Kumar SP: Virus-induced gene silencing in tomato. Plant J 2002, 31:777-786

61. Velasquez AC, Chakravarthy S, Martin GB: Virus-induced gene silencing (VIGS) in Nicotiana benthamiana and tomato. J Vis Exp 2009, 28:e1292.

62. de Hoon MJ, Imoto S, Nolan J, Miyano S: Open source clustering software. Bioinformatics 2004, 20:1453-1454.

63. Boyle El, Weng S, Gollub J, Jin H, Botstein D, Cherry JM, Sherlock G: GO:: TermFinder - open source software for accessing Gene Ontology information and finding significantly enriched Gene Ontology terms associated with a list of genes. Bioinformatics 2004, 20:3710-3715.

64. Darriba D, Taboada GL, Doallo R, Posada D: jModelTest 2: more models, new heuristics and parallel computing. Nat Methods 2012, 9:772.

65. Guindon S, Gascuel O: A simple, fast, and accurate algorithm to estimate large phylogenies by maximum likelihood. Syst Biol 2003, 52:696-704.

66. Abascal F, Zardoya R, Posada D: ProtTest: selection of best-fit models of protein evolution. Bioinformatics 2005, 21:2104-2105.

67. Gouy M, Guindon S, Gascuel O: SeaView version 4: a multiplatform graphical user interface for sequence alignment and phylogenetic tree building. Mol Biol Evol 2010, 27:221-224.

68. FigTree. http://tree.bio.ed.ac.uk/software/figtree/.

69. Oliveros JC: VENNY. An interactive tool for comparing lists with Venn diagrams. 2007. http://bioinfogp.cnb.csic.es/tools/venny/.

70. Bombarely A, Menda N, Tecle IY, Buels RM, Strickler S, Fischer-York T, Pujar A, Leto J, Gosselin J, Mueller LA: The Sol Genomics Network (solgenomics.net): growing tomatoes using Perl. Nucleic Acids Res 2011, 39:D1149-D1155.

71. Nguyen HP, Chakravarthy S, Velasquez AC, McLane HL, Zeng L, Nakayashiki $\mathrm{H}$, Park DH, Collmer A, Martin GB: Methods to study PAMP-triggered immunity using tomato and Nicotiana benthamiana. Mol Plant Microbe Interact 2010, 23:991-999.

72. Liu D, Shi L, Han C, Yu J, Li D, Zhang Y: Validation of reference genes for gene expression studies in virus-infected Nicotiana benthamiana using quantitative real-time PCR. PLoS One 2012, 7:e46451.

doi:10.1186/gb-2013-14-12-r139

Cite this article as: Rosli et al:: Transcriptomics-based screen for genes induced by flagellin and repressed by pathogen effectors identifies a cell wall-associated kinase involved in plant immunity. Genome Biology 2013 14:R139.

\section{Submit your next manuscript to BioMed Central and take full advantage of:}

- Convenient online submission

- Thorough peer review

- No space constraints or color figure charges

- Immediate publication on acceptance

- Inclusion in PubMed, CAS, Scopus and Google Scholar

- Research which is freely available for redistribution 